\title{
Seasonal variation of wool fibre length in Karagouniko and Chios sheep in relation to meteorological factors
}

\author{
Aristidis Matsoukis*, George Stratakos, Aikaterini Chronopoulou-Sereli, loannis Tsiros \\ Department of Crop Science, School of Plant Sciences, Agricultural University of Athens, 75 lera Odos St., 11855, Athens, Greece
}

\author{
A B S T R A C T
}

\begin{abstract}
Karagouniko and Chios sheep breeds present a lot of advantages on the implementation of sheep farming in Greece, a country with diverse relief resulting in a microclimatic variety, but nothing is known about the impact of season, as the outcome of important meteorological variables, on the fibre length growth (FLG) of the aforementioned breeds. Thus, the effect of season (Winter, Spring, Summer, Autumn) on the FLG of these breeds (by using analysis of variance) was studied in the Artificial Insemination Center of Karditsa $\left(39^{\circ} 21^{\prime} 18^{\prime \prime} \mathrm{N}\right.$, $21^{\circ} 54^{\prime} 19^{\prime \prime}$ E), Periphery of Thessaly, Greece, combined with a correlation analysis between FLG of each examined sheep breed and each of the studied meteorological variables, air temperature (AIRT), relative humidity (RH), sunshine (SUNS) and rainfall (R) for a two-year period. It was found that the FLG of Karagouniko sheep was significantly higher than the respective growth of Chios sheep, for each examined season, while the descending order of seasonal FLG for both breeds was Winter $>$ Spring $>$ Autumn $>$ Summer. Fibre length growth of Karagouniko and Chios breeds correlated negatively with AIRT and SUNS and positively with RH, implying a better FLG in cooler, more overcast and wetter time periods. Our study adds new knowledge concerning the effect of season, and particularly, the effect of the aforementioned meteorological variables on the wool growth of two considerable sheep breeds in Greece, Karagouniko and Chios, opening up new horizons for their exploitation.
\end{abstract}

Keywords: Air temperature; Chios sheep; Karagouniko sheep; Seasonal variation; Wool fibre length

\section{INTRODUCTION}

Wool is one of the products of sheep (Wiedemann et al., 2015; Zygoyiannis, 2006) and perhaps the first product used by man since their domestication. Their unshorn skins comprised the first clothing of man and are used even today by the inhabitants of many, mainly mountainous, areas for their protection from the adverse weather conditions during winter. For a long time, the natural sheep's wool was the only raw material for the creation of wooly clothes and the objective of international trade with great economic importance. Even now, after the discovery of cheap and easily coloured synthetic fibres, various prime sheep wool are used for the production of high quality fabrics (Zygoyiannis, 2014). In addition, the properties of wool fabrics such as inherent breathability and adaptability to climate cannot be matched with synthetic fibres (Gowane et al., 2017).

The quantity and the quality of wool provided by sheep depends on its genotype (Zygoyiannis, 2014), reaching a maximum when the various factors of farming are extremely satisfactory. Important components of the quality of sheep wool are the colour, length and diameter of fibre as well as its thinness and curliness (Mendel, 2010). Another important determinant of sheep wool quality is staple length influencing the type of manufacturing process. Staple length is determined by the extent of crimping and individual fibre length (Khan et al., 2012).

Sheep fibre length is affected by the aerial environment where sheep grows, especially, meteorological factors, among others. It has been reported a retardation of length growth rate of sheep wool by low temperatures (Khan et al., 2012). On the other hand, Schlink et al. (1996) reported increased fibre length in a period with low temperatures whereas Elsherbiny et al. (1978) reported a coincidence of high temperature with smaller increases in sheep fibre length. The same authors reported also higher increases in sheep fibre length under normal light compared to dim light. Furthermore, greater hair length of Morada Nova sheep was reported in a period characterized by higher temperature and lower relative humidity values,

*Corresponding author:

Aristidis Matsoukis, Department of Crop Science, School of Plant Sciences, Agricultural University of Athens, 75 lera Odos St., 11855 ,

Athens, Greece. E-mail: armatsoukis@aua.gr

Received: 11 July 2019;

Accepted: 22 September 2019 
namely the dry period, in comparison to the rainy period in a semiarid region of Brazil (Costa et al., 2018), that is, a seasonal variation of the aforementioned sheep variable. In addition, a seasonal variation of wool fibre length was confirmed for New Zealand Romney sheep with maximum and minimum values occuring in summer and winter, respectively (Woods and Orwin, 1988).Karagouniko is a popular sheep breed with the greatest population in Greece (Koutsouli, 2015; Rogdakis, 2002). It is a fairly durable breed with important capabilities for meat and milk production (Efstathiou, 1996). Chios is another indigenous very good but rare sheep breed in Greece with satisfactory performance in meat (Mendel, 2010) and milk production (Rogdakis, 2002). Both breeds have been used in many genetic improvement programs in Greece with encouraging results (Zygoyiannis, 2014) raising, in general, the level of sheep production both quantitatively and qualitatively (Alkass et al., 1991). Up to now, however, the quality of wool in Karagouniko and Chios breeds is, in general, low and of small economic importance, in agreement with Koutsouli (2015). Therefore, keeping also in mind the great importance of these two breeds for sheep farming in Greece, there is a lack of literature regarding the association of meteorological parameters with the wool length of both breeds as well as the seasonal variation of this variable.

The purpose of the present study is then to investigate the possible association of selected meteorological variables with the growth of wool fibre length in Karagouniko and Chios breeds. The considered meteorological parameters are: air temperature (AIRT), sunshine (SUNS), relative humidity (RH) and rainfall (R). In addition, research included the investigation of the possible effect of season on the wool fibre length of the aforementioned sheep breeds. The testing of the hypothesis of the seasonal variation of wool fibre length may be a first step for understanding the role of the aerial environment on the wool length of these important sheep breeds.

\section{MATERIALS AND METHODS}

\section{Study area and experimental material}

Research was carried out in the Artificial Insemination Center of Karditsa Municipality (39021'18' 'N, $21^{0} 54^{\prime} 19^{\prime}$ 'E), Periphery of Thessaly, Greece, from March 2004 to February 2006, that is, a two-year period. The farm of the aforementioned Center is located about 2 $\mathrm{Km}$ away from the center of the city of Karditsa. Twelve experimental rams (Ovis aries L.), about six years old, with an initial live weight of $75.4 \pm 3.1 \mathrm{Kg}$ (mean \pm SD), were living in the aforementioned farm. Six of them belonged to Karagouniko sheep breed and the others to Chios sheep breed.
All animals were fed on a balanced diet based on their nutritional needs, according to their physiological changes and season of the year. Specifically, apart from their grazing during their roaming freely within the farm in daytime, rams were fed also on dehydrated alfalfa hay, barley, corn, soybean, minerals and vitamins. The access of animals to fresh water was free. In any case, however, their nutritional management was uniform. The good nutritional status and health of rams were confirmed by the aid of haematological and endocrinological tests once a month during the whole experimental period. The rams were housed in individual pens (indoors) in nighttime.

\section{Meteorological data collection and processing}

Air temperature and RH were recorded continually every 6 min by two sensors each one with a data logger (Chronopoulos et al., 2012), during the whole experimental period. An instrument (consisted of a sensor and a datalogger) was placed indoors and the other outdoors for providing a detailed picture of the environment of the experimental rams, in terms of both AIRT and RH.

The aforementioned instruments, before their installation in the measurement sites, were calibrated in the laboratory against reference sensors and tested for a period of five days. Additionally, every six months, the instruments were tested in situ against reference sensors. The AIRT and RH differences among the sensors of the experiment and the reference sensors were not higher than $0.1^{\circ} \mathrm{C}$ and $3 \%$, respectively, and were taken appropriately into account (Matsoukis et al., 2018a). The installed sensors were enclosed in appropriate shelters screened from precipitation and direct solar radiation and placed $1.5 \mathrm{~m}$ above ground surface (Matsoukis et al., 2018b).

Sunshine and $\mathrm{R}$ data were provided by the meteorological station of the Tobacco Station of Agricultural Research, adjacent to the farm. Averages on a month-basis and also for each season (Spring, Summer, Autumn and Winter) of the recorded and provided meteorological data were estimated and used in the present analysis.

\section{Fibre length measurements and processing}

Fibre length measurements were conducted manually once a month (on its first day) with the aid of a ruler for the whole studied period. Specifically, for each measurement, ten fibre samples from the left mid-side area (Salehian et al., 2015), individually for each ram, were taken into consideration. Each fibre sample was consisted approximately of the same number of fibres by appropriately using a clip fastened firmly with a particular number of fibres; exceedance of this number forced the clip to open automatically.

The fibre length of each sample (after the successful fastening of the clip every time with the maximum number of fibres it could hold) was measured at its top after 
pulling slightly the clip resulting in their straightening. All experimental sheep were shorn by hand annually on May $1^{\text {st }}$, immediately after the relevant measurement. From the fibre length measurements, fibre length growth (FLG) was estimated as the difference between adjacent months. From the FLG data, averages were estimated for each examined breed, month and season for the whole studied period.

\section{Statistical analysis}

To investigate the role of breed and season on FLG, a completely randomized design (Tufik et al., 2019) with two factors (Matsoukis et al., 2018c) was applied. The first factor included two levels, each corresponding to each studied breed (Karagouniko and Chios) and the second factor included four levels, each corresponding to each studied season (Spring, Summer, Winter and Autumn), for the whole examined time period.

Analysis revealed no significant interaction $(\mathrm{P}>0.05)$ between the two factors and thus, one-way ANOVA (Matsoukis et al., 2015a) was performed to all FLG data, including both examined breeds and seasons, with means comparison by Tukey's HSD test (Kaltsikes, 1997; Matsoukis et al., 2015b).

Also, a linear correlation (Pearson's) analysis (Matsoukis et al., 2018b; Roussos et al., 2007) was carried out to detect possible relationships between FLG of each examined sheep breed (Karagouniko and Chios) and each of the studied meteorological variables (AIRT, RH, SUNS and R) using monthly averages for the whole time period. The statistics was performed using IBM SPSS Statistics 21 and MS Excel 2003 with results to be considered significant at $\mathrm{P} \leq 0.05$.

\section{RESULTS AND DISCUSSION}

The averages, on a month-basis, for AIRT, RH, SUNS and $\mathrm{R}$ ranged from $4.4^{\circ} \mathrm{C}$ (January) to $28.1^{\circ} \mathrm{C}$ (July), $57.3 \%$ (July) to $86.3 \%$ (December), $79.4 \mathrm{~h}$ (December) to $326.0 \mathrm{~h}$ (July) and $2.0 \mathrm{~mm}$ (August) to $132.0 \mathrm{~mm}$ (December), respectively, taking into consideration the whole studied period. The total fibre length of Karagouniko and Chios sheep, from the beginning until the end of the experimental period, was $54.0 \mathrm{~cm}$ and $40.3 \mathrm{~cm}$, respectively. The longer fibre of Karagouniko breed (by almost $14 \mathrm{~cm}$ ), compared to Chios breed, may be attributed to its different genetic potential (in comparison to Chios), and not to their living conditions, since both breeds were treated in the same way.

The seasonal changes of AIRT, RH, SUNS and R for the whole experimental period are shown in Fig. 1. As expected, Summer was the warmest and sunniest season with mean values of AIRT and SUNS reaching a maximum, almost

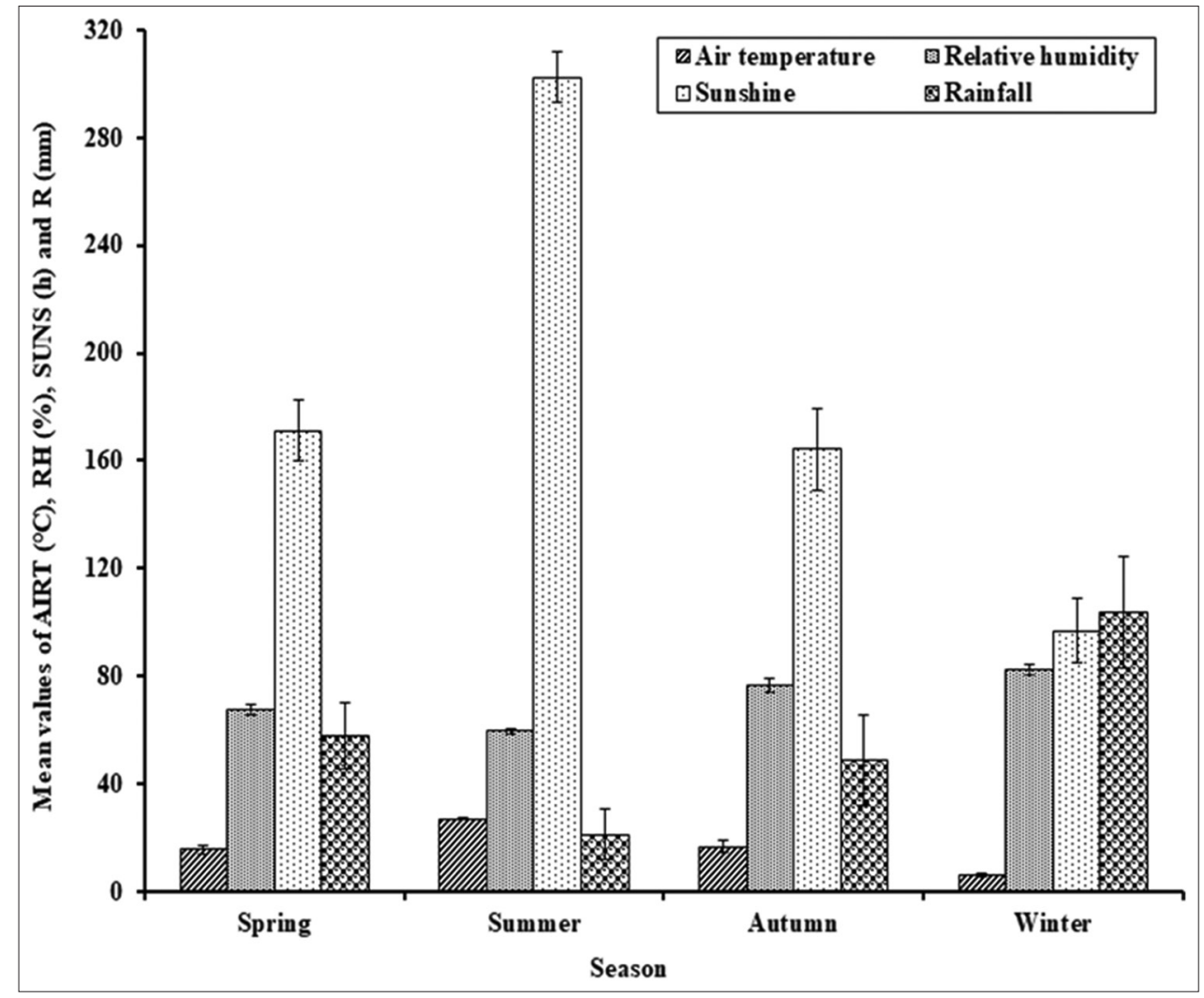

Fig 1. Seasonal changes of air temperature (AIRT), relative humidity $(R H)$, sunshine (SUNS) and rainfall $(R)$ for the whole experimental period. Vertical bars indicate the standard error of the mean. 
$27.0^{\circ} \mathrm{C}$ and $303.0 \mathrm{~h}$, respectively. Winter was the coldest and most overcast season (mean values of AIRT and SUNS decreased by $78 \%$ and $68 \%$, respectively, compared to the respective values of Summer). Relative humidity and $\mathrm{R}$ presented their highest and lowest mean values in Winter and Summer (RH and R decreased by almost $28 \%$ and $80 \%$, respectively, compared to the respective values of Winter), respectively. Concerning the intermediate seasons, Autumn was slightly warmer and more overcast than Spring. Mean $\mathrm{RH}$ took greater value in Autumn compared to Spring as did R in Spring compared to Autumn.

Analysis of variance to the all FLG data per season for the studied breeds of sheep (Table 1) confirmed the existence of significant differences regarding the aforementioned parameter.

Table 1: Analysis of variance for effects of time on the fibre length growth of Karagouniko and Chios sheep

\begin{tabular}{lccc}
\hline \multicolumn{4}{c}{ Fibre length growth $(\mathrm{cm})$} \\
\hline & dfa & Mean square & Variance ratio \\
\hline Time $^{\text {b }}$ & 7 & 1.789 & $12.233^{\star \star *}$ \\
Residual $^{*}$ & 88 & 0.146 & - \\
\hline
\end{tabular}

${ }^{a}$ df: degrees of freedom, ${ }^{\mathrm{T} T i m e: ~ S e a s o n ~(S p r i n g, ~ S u m m e r, ~ A u t u m n, ~ W i n t e r), ~}$ $" *$ : significance at $P \leq 0.001$

Table 2: Pearson's linear correlation coefficients of the monitored meteorological factors with the fibre length growth of Karagouniko and Chios sheep

\begin{tabular}{lllll} 
& AIRT $^{\mathrm{a}}$ & $\mathbf{R H}^{\mathrm{b}}$ & SUNSc & $\mathbf{R}^{\mathrm{d}}$ \\
\hline Sheep & & & & \\
Karagouniko & $-0.458^{*}$ & $0.503^{*}$ & $-0.458^{*}$ & $\mathrm{Ns}$ \\
Chios & $-0.573^{* *}$ & $0.420^{*}$ & $-0.484^{*}$ & $\mathrm{Ns}$ \\
\hline
\end{tabular}

${ }^{a}$ AIRT: Air temperature, ${ }^{b} \mathrm{RH}$ : Relative humidity, ${ }^{\circ} \mathrm{SUNS}$ : Sunshine,

dR: Rainfall, ", ": significance at $P \leq 0.05$ and $P \leq 0.01$, respectively, ns: not significant
Fibre length growth showed its highest, numerically, value in Winter, significantly different from the respective values of the other seasons in the overwhelming majority of the cases (except Spring), for both Karagouniko and Chios (Fig. 2). On the other hand, the lowest FLG value, was confirmed in Summer, however, with no significant differences $(\mathrm{P}>0.05)$ between the aforementioned season and each intermediate season (Spring and Autumn), irrespective of breeds. From a purely numerical point of view, the descending order of seasonal FLG for both Karagouniko and Chios was Winter $>$ Spring $>$ Autumn $>$ Summer. The FLG of Karagouniko sheep was significantly higher than the respective growth of Chios sheep, when examining each season separately (Fig. 2).

The linear correlation analysis revealed that the FLG, individually for Karagouniko and Chios rams, correlated significantly with almost all meteorological variables (Table 2). The correlation was positive in the case of RH and negative in the cases of AIRT and SUNS. This negative correlation can be explained, in general, by the coincidence of the higher values of FLG (for each examined breed) with a decrease of the values of the last two meteorological variables and vice versa, in accordance with Elsherbiny et al. (1978) who reported that higher temperature coincided with smaller increases in sheep fibre length. It seems that the FLG of both Karagouniko and Chios sheep was favoured in time periods where AIRT and SUNS took relatively low values, in general, as in the cases of Winter and Spring. The positive correlation of RH with FLG can be attributed merely to the fact that an increase in $\mathrm{RH}$ results to increase of the fibre length (Chronopoulou-Sereli et al., 2001).

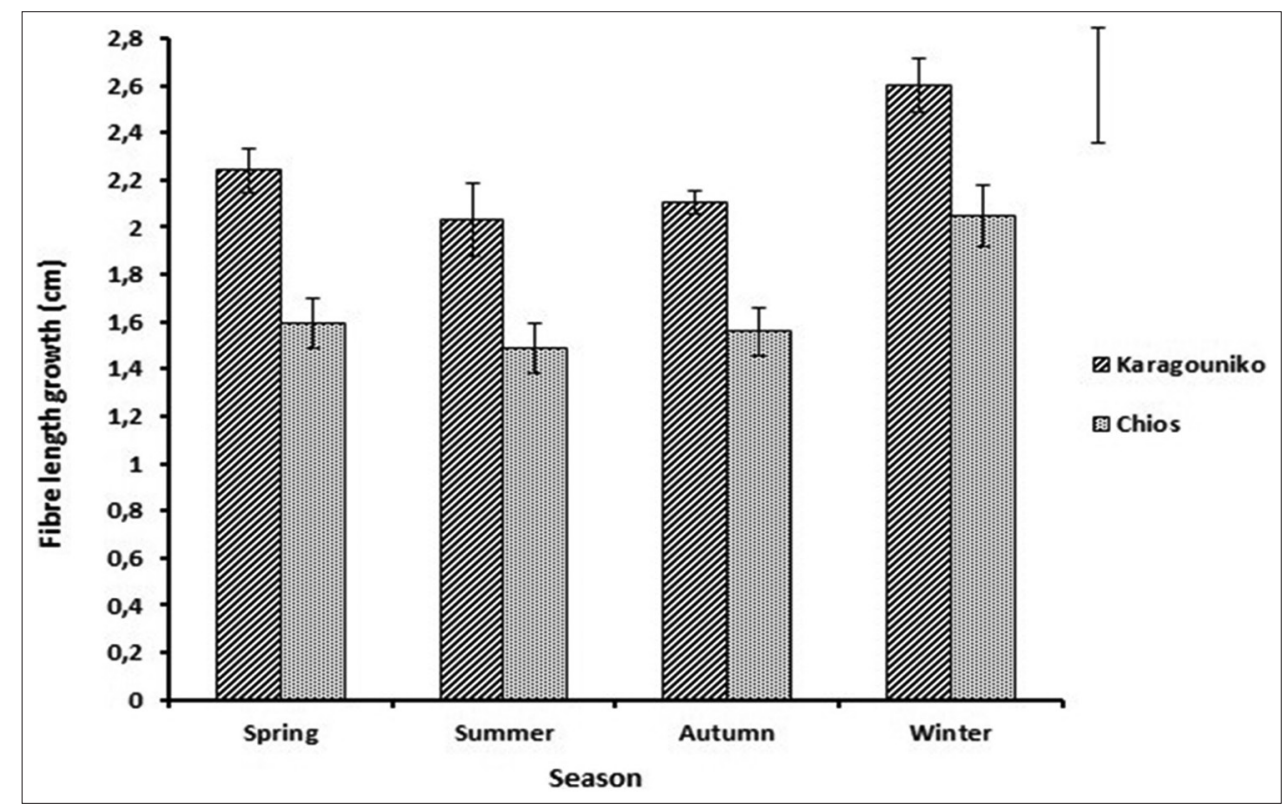

Fig 2. Effect of time (season) on the fibre length growth of Karagouniko and Chios sheep. In each column the bar on it represents the standard error of the mean $(n=12)$. The vertical bar at the right represents the Tukey's HSD value at $P=0.05$. 
The higher FLG in Winter and Spring, taking into account the absence of significant difference between these seasons, as already mentioned, for both Karagouniko and Chios breeds, is in accordance with the results of Schlink et al. (1996) who reported increased fibre length in Merino wethers of two phenotypes (low and high staple lengths) in the aforementioned seasons, compared to Summer and Autumn. Also, Schlink et al. (1999) reported significant changes of FLG in Merino sheep (Australia), associated with time of year and ranged from $454 \mathrm{~mm} /$ day (Spring) to $351 \mathrm{~mm} /$ day (Autumn). On the other hand, Woods and Orwin (1988) reported maximum and minimum values of mean length growth in Summer and Autumn, respectively, for Romney sheep (New Zealand), confirming, however, in general, seasonality of this parameter as in our results (regarding purely numerical values). It has also been reported that fibre length shows seasonal variation in the majority of cases (SGS WOOL TESTING SERVICES, 2011).

The results of our work is a first step for understanding the way meteorological variables such as the ones studied affect the growth of wool, in terms of FLG, for two important sheep breeds in Greece. The aforementioned understanding could contribute to the proper human involvement towards a more rational exploitation of these breeds in Greece and also in other countries too.

\section{CONCLUSIONS}

To sum up, FLG of both Karagouniko and Chios sheep was affected by the season of the year, with the descending order (from a purely numerical point of view) of seasonal FLG for both Karagouniko and Chios to be Winter $>$ Spring $>$ Autumn $>$ Summer. The FLG of Karagouniko sheep was significantly higher than the respective growth of Chios sheep, when examining each season separately. Fibre length growth of both Karagouniko and Chios breeds correlated positively with RH and negatively with AIRT and SUNS. Our study offers new perspectives for the understanding of the effect of season, and particularly, of the aforementioned meteorological variables on the wool growth of two considerable sheep breeds in Greece, Karagouniko and Chios, opening potentially the way for their more rational utilization.

\section{ACKNOWLEDGEMENTS}

Authors want to thank Mr. M. Pagonis (member of the Special Technical Laboratory Staff, Agricultural University of Athens) for his help regarding the completion of the graphs. This work has been partly funded by the State Scholarships Foundation of Greece.

\section{Author's contributions}

A.M. evaluated and analyzed the data, evaluated the results, planned and wrote the manuscript; G.S. conceived and carried out the experiment; A.C.-S. was involved in the general planning and supervision and in the evaluation of the data and the results; I.T. was involved in the general planning and editing. All authors read and approved the final manuscript.

\section{REFERENCES}

Alkass, J. E., D. A. Aziz and H. N. Hermiz. 1991. Genetic parameters of growth traits in Awassi sheep. Emir. J. Agric. Sci. 3: 152-161.

Chronopoulos, K. I., A. P. Kamoutsis and A. S. Matsoukis. 2012. Thermal comfort estimation in relation to different orientation in mountainous regions in Greece by using artificial neural networks. Glob. Nest J. 14: 532-539.

Chronopoulou-Sereli, A., I. Tsiros and A. Kamoutsis. 2001. Laboratory Exercises of Meteorology. Agricultural University of Athens, Athens, Greece.

Costa, W. P., E. C. P. Filho, J. H. G. Leite, W. S. T. Silva, W. E. D. Silva, F. H. S. Lima, G. N. A. Júnior and D. A. E. Façanha. 2018. Coat characteristics and physiological responses of locally adapted ewes in semiarid region of Brazil. Semin. Ciênc. Agrár. 39: 1281-1294.

Efstathiou, L. 1996. The Sheep. Efstathiou Publications, Athens, Greece.

Elsherbiny, A. A., H. A. Eloksh, A. S. Elsheikh and M. H. Khalil. 1978. Effect of light and temperature on wool growth. J. Agric. Sci. 90: 329-334.

Gowane, G. R., Y. P. Gadekar, V. Prakash, V. Kadam, A. Chopra and L. L. L. Prince. 2017. Climate change impact on sheep production: Growth, milk, wool, and meat. In: V. Sejian, J. Gaughan, S. M. K. Naqvi, R. Bhatta, P. K. Malik and R. Lal (Eds.), Sheep Production Adapting to Climate Change, Springer, Singapore, pp. 31-69.

Kaltsikes, P. I. 1997. Simple Experimental Designs, Agricultural Experimentation. Stamoulis Publications, Thessaloniki, Greece.

Khan, M. J., A. Abbas, M. Ayaz, M. Naeem, M. S. Akhter and M. H. Soomro. 2012. Factors affecting wool quality and quantity in sheep. Afr. J. Biotechnol. 11: 13761-13766.

Koutsouli, P. 2015. Sheep Shed. Farmed Breeds-Rearing SitesNutrition-Reproduction-Births-Breastfeeding and Weaning-Milk Production-Keeping of Statistics-Vaccinations-Shearing-Cutting of Nails. Agricultural University of Athens, Athens, Greece.

Matsoukis, A., D. Gasparatos and A. Chronopoulou-Sereli. 2015a. Micronutrient content in relation to specific leaf area, light regime and drenched-applied paclobutrazol in Lantana camara L. Curr. Agri. Res. J. 3: 101-104.

Matsoukis, A., D. Gasparatos and A. Chronopoulou-Sereli. 2015b. Mepiquat chloride and shading effects on specific leaf area and $\mathrm{K}, \mathrm{P}, \mathrm{Ca}, \mathrm{Fe}$ and $\mathrm{Mn}$ content of Lantana camara L. Emir. J. Food Agric. 27: 122-126.

Matsoukis, A., A. Kamoutsis and A. Chronopoulos. 2018a. Estimation of the meteorological forest fire risk in a mountainous region by using remote air temperature and relative humidity data. Int. Lett. Nat. Sci. 67: 1-8.

Matsoukis, A., A. Kamoutsis and A. Chronopoulou-Sereli. 2018b. Air temperature effect on end of flowering of Cirsium arvense (L.) Scop. in a mountainous region of Greece. J. Anim. Plant Sci. 28: 100-106. 
Matsoukis, A., A. Kamoutsis and A. Chronopoulou-Sereli. 2018c. A note on the flowering of Ajuga orientalis $\mathrm{L}$. in relation to air temperature in Mount Aenos (Cephalonia, Greece). Curr. Agri. Res. J. 6: 261-267.

Mendel, C. 2010. Practical Sheep Farming. Rearing-ReproductionBreeds-Hygiene-Products-Legislation. Vasdekis Publications, Athens, Greece.

Rogdakis, E. 2002. Indigenous Breeds of Sheep. DescriptionPhylogeny-Genetic Improvement-Preservation. Agrotypos Publications, Athens, Greece.

Roussos, P., A. Matsoukis, C. Pontikis and A. Chronopoulou-Sereli. 2007. Relations of environmental factors with the phenol content and oxidative enzyme activities of olive explants. Sci. Hortic. 113: $100-102$.

Salehian, Z., N. Naderi, M. Souri, R. Mirmahmoudi and F. Hozhabri. 2015. Seasonal variation of fibre follicle activity and wool growth in fat-tailed Sanjabi sheep in west Iran. Trop. Anim. Health Prod. 47: 567-573.

Schlink, A. C., G. Mata, J. Lea and A. J. M. Ritchie. 1996. Seasonal Variation in Fibre Diameter and Length Growth Rate in High and Low Staple Strength Merino Wethers. Proceedings of the Australian Society of Animal Production. Vol. 21. p. 356.

Schlink, A. C., G. Mata, J. M. Lea and A. J. M. Ritchie. 1999. Seasonal variation in fibre diameter and length in wool of grazing Merino sheep with low or high staple strength. Aust. J. Exp. Agric. 39: 507-517.

SGS WOOL TESTING SERVICES. 2011. Fibre Length Diameter Profiles. Info Bulletin. Vol 1.5. Available from: https://www.sgs. co.nz/ /media/Local/New\%20Zealand/Documents/Technical\%20 Documents/Technical\%20Bulletins/Wool\%20Testing\%20Info\%20 Bulletins/SGS-AGRI-1-5-Fibre-Length-Diameter-Profiles-A4EN-11-11.pdf. [Last accessed on 2019 Jul 23].

Tufik, C. B. A., P. C. R. Fontes, C. D. C. Milagres and M. A. Moreira. 2019. Productivity of potato seed submitted to different doses of potassium in hydroponic system. Emir. J. Food Agric. 31: 555-560.

Wiedemann, S. G., S. F. Ledgard, B. K. Henry, M. J. Yan, N. Mao and S. J. Russell. 2015. Application of life cycle assessment to sheep production systems: Investigating co-production of wool and meat using case studies from major global producers. Int. J. Life Cycle Assess. 20: 463-476.

Woods, J. L. and D. F. G. Orwin. 1988. Seasonal variations in the dimensions of individual Romney wool fibres determined by a rapid autoradiographic technique. N. Z. J. Agric. Res. 31: 311-323.

Zygoyiannis, D. 2006. Sheep production in the world and in Greece. Small Rumin. Res. 62: 143-147.

Zygoyiannis, D. 2014. Sheep Farming. $3^{\text {rd }}$ ed. Modern Education Publications, Thessaloniki, Greece. 